\title{
Long-Term Cost-Effectiveness the Dexcom G6 Real- Time Continuous Glucose Monitoring System Compared with Self-Monitoring of Blood Glucose in People with Type 1 Diabetes in France
}

Stéphane Roze · John J. Isitt · Jayne Smith-Palmer · Peter Lynch •

Brigitte Klinkenbijl · Gerald Zammit · Pierre-Yves Benhamou

Received: September 16, 2020 / Accepted: October 23, 2020 / Published online: November 9, 2020

(C) The Author(s) 2020

\section{ABSTRACT}

Introduction: The aim was to determine the long-term cost-effectiveness of the Dexcom G6 real-time continuous glucose monitoring (RTCGM) system versus self-monitoring of blood glucose (SMBG) in adults with type 1 diabetes (T1D) in France.

Methods: The analysis was performed using the IQVIA Core Diabetes Model and utilized clinical input data from the DIAMOND clinical trial in adults with T1D. Simulated patients were assumed to have a mean baseline HbA1c of $8.6 \%$, and those in the RT-CGM arm were

S. Roze $\cdot$ J. J. Isitt

Vyoo Agency, Lyon, France

J. Smith-Palmer ( $\square)$

Ossian Health Economics and Communications, Basel, Switzerland

e-mail: smith-palmer@ossianconsulting.com

P. Lynch

Dexcom, San Diego, CA, USA

B. Klinkenbijl

Dexcom, Essertines-sur-Rolle, Switzerland

G. Zammit

Dexcom, Reading, UK

P.-Y. Benhamou

Department of Endocrinology, Grenoble Alpes

University Hospital, Grenoble, France assumed to have a $\mathrm{HbA} 1 \mathrm{c}$ reduction of $1.0 \%$ compared with $0.4 \%$ in the SMBG arm. A quality of life (QoL) benefit associated with a reduced fear of hypoglycemia (FoH) and elimination of the requirement for fingerstick testing in the RT-CGM arm was also applied.

Results: The G6 RT-CGM system was associated with an incremental gain in quality-adjusted life expectancy of 1.38 quality-adjusted life years (QALYs) compared with SMBG (10.64 QALYs versus 9.23 QALYs). Total mean lifetime costs were 21,087 euros higher with RT-CGM (148,077 euros versus 126,990 euros), resulting in an incremental cost-effectiveness ratio of 15,285 euros per QALY gained.

Conclusions: In France, based on a willingnessto-pay threshold of 50,000 euros per QALY gained, the use of the G6 RT-CGM system is cost-effective relative to SMBG for adults with long-standing T1D, driven primarily by improved glycemic control and the QoL benefit associated with reduced $\mathrm{FoH}$ and elimination of the requirement for fingerstick testing.

Keywords: Cost-effectiveness; France; Realtime continuous glucose monitoring; Type 1 diabetes 


\section{Key Summary Points}

Why carry out this study?

Real-time continuous glucose monitoring (RT-CGM) can help improve disease management in people with type 1 diabetes (T1D), particularly those with problematic hypoglycemia or a fear of hypoglycemia

The Dexcom G6 RT-CGM system is one of the most advanced RT-CGM systems available but studies on the long-term cost-effectiveness of this system are lacking

\section{What was learned from the study?}

Using clinical input data from the DIAMOND trial, for people with longstanding T1D the use of the G6 RT-CGM system was projected to improve qualityadjusted life expectancy relative to selfmonitoring of blood glucose (SMBG)

In France, over a lifetime time horizon the G6 RT-CGM system is likely to be costeffective compared with SMBG for individuals with long-standing T1D

\section{DIGITAL FEATURES}

This article is published with digital features to facilitate understanding of the article. You can access the digital features on the article's associated Figshare page. To view digital features for this article go to https://doi.org/10.6084/m9. figshare.13128965.

\section{INTRODUCTION}

For adults with type 1 diabetes (T1D) treated with multiple daily injections of insulin (MDI), the use of real-time continuous glucose monitoring (RT-CGM) has been shown to improve glycemic control relative to self-monitoring of blood glucose (SMBG), with the magnitude of improvement being greatest in those with the poorest glycemic control at baseline $[1,2]$. In the DIAMOND trial, which compared the Dexcom G4 RT-CGM system with SMBG in adults with T1D (with a mean baseline HbA1c of $8.6 \%$ [70 $\mathrm{mmol} / \mathrm{mol}])$, the mean reduction in $\mathrm{HbA} 1 \mathrm{c}$ at week 24 was $1.0 \%(10 \mathrm{mmol} / \mathrm{mol})$ in the RTCGM group versus $0.4 \%(5 \mathrm{mmol} / \mathrm{mol})$ in the SMBG group [1]. Alongside improved glycemic control, findings from the DIAMOND trial also showed that, compared with SMBG alone, RTCGM significantly reduced the incidence of hypoglycemic events, decreased the proportion of time spent in hypoglycemia and improved patient-reported outcomes (PROs) such as diabetes distress and fear of hypoglycemia $(\mathrm{FoH})$ $[3,4]$.

The DIAMOND trial was performed using the G4 RT-CGM system. Since then, the technology involved in RT-CGM has advanced, and the more recently introduced Dexcom G6 RT-CGM system has several additional features that may offer incremental clinical and quality of life (QoL) benefits as well as overcoming limitations associated with previous generation RT-CGM devices. In particular, limitations associated with older RT-CGM systems include the requirement for frequent calibration, lack of customizable alarm settings and no facility for remote monitoring or connectivity to mobile devices. In some instances, such limitations have hindered patient acceptance of RT-CGM despite its established clinical benefits [5]. The G6 RT-CGM system is the first stand-alone RTCGM device to incorporate factory calibration, which negates the need for using fingerstick testing for daily calibrations. Another major innovation with the G6 system relative to earlier generation devices is the Urgent Low Soon Alert. This feature alerts the user if blood glucose levels are predicted to drop $<55 \mathrm{mg} / \mathrm{dl}$ within the next $20 \mathrm{~min}$, allowing the user to take pre-emptive action to avoid a hypoglycemic event. Although head-to-head clinical trials of the G6 RT-CGM device versus earlier generation CGM systems are lacking, recently published real-world data comparing the Dexcom G5 and G6 RT-CGM systems have shown that the addition of the Urgent Low Soon Alert 
led to a significant reduction in the proportion of time spent in the hypoglycemic range compared with the G5 system [6]. Additionally, the G6 system also has the facility to directly transmit data to a smart phone, allowing discreet monitoring of glucose levels and also remote monitoring of a user's glucose levels by a parent or caregiver. Remote monitoring has been reported to alleviate anxiety in the parents of young children with T1D, particularly around nocturnal hypoglycemic events [7]. The benefits of remote monitoring are also acknowledged in a 2018 French position statement on CGM, which notes that the facility for real-time transmission of data should be taken into account when initiating RT-CGM in children and non-autonomous or isolated adults [8].

The 2018 French position statement recommends the use of RT-CGM for people with T1D who experience major hypoglycemic problems, which includes individuals with a history of severe hypoglycemic events (SHEs), unawareness of hypoglycemia or a pronounced $\mathrm{FoH}$ [8]. In France, it is estimated that between 22,400 and 40,000 people per year may be eligible to use the G6 RT-CGM system [9]. One of the commitments stipulated in the French National Health Strategy for 2018-2022 is to guarantee prompt and universal access to innovations such as new medical devices [10]. However, there are increasing financial pressures within many health systems, meaning that the cost of innovative technologies should be justified by a sufficient clinical benefit to supersede currently available technologies. In view of the incremental clinical and QoL benefits afforded by the Dexcom G6 RT-CGM system, a long-term costeffectiveness analysis was performed to determine the cost-effectiveness of RT-CGM versus SMBG in adults with T1D in France.

\section{METHODS}

\section{Model Structure}

The analysis was performed using the IQVIA CORE Diabetes Model (CDM, version 9.0 E360). The CDM is a non-product specific and extensively validated computer simulation model that can be used to project long-term clinical and economic outcomes in patients with type 1 or type 2 diabetes. The CDM is based on a series of interdependent sub-models that simulate the long-term progression of diabetes and related complications including cardiovascular, renal and ophthalmic complications and diabetic foot. The sub-models have a semi-Markov structure and use time, time-in-state and diabetes type-dependent probabilities to project long-term disease progression. Comprehensive details of the model structure have been previously published by Palmer et al. [11, 12]. Model outcomes include life expectancy, quality-adjusted life expectancy, cumulative incidence of long-term complications, mean time to onset of complications, direct and indirect costs and the incremental cost-effectiveness ratio (ICER).

\section{Simulation Cohort and Treatment Effects}

The analysis was performed using clinical input data from the DIAMOND trial in adults with T1D [1]. The DIAMOND trial was a randomized controlled trial that compared outcomes in patients randomly allocated to either RT-CGM using the G4 system or SMBG alone for 24 weeks. For inclusion, patients were required to be aged $\geq 25$ years with $\mathrm{HbA} 1 \mathrm{c}$ of $7.5-10.0 \%$ $(58-86 \mathrm{mmol} / \mathrm{mol})$ and treated with MDI for at least 1 year previously and with no history of personal CGM use. Baseline characteristics of the simulated patient cohort were based on the DIAMOND trial population and supplemented

Table 1 Baseline cohort characteristics

\begin{tabular}{ll}
\hline Characteristics & \\
\hline Mean (SD) age (years) & $47.6(12.7)$ \\
Mean (SD) duration of diabetes (years) & $20.3(13.6)$ \\
Proportion male (\%) & 56 \\
Mean (SD) HbAlc (\%) & $8.6(0.65)$ \\
Mean (SD) body mass index $\left(\mathrm{kg} / \mathrm{m}^{2}\right)$ & $27.5(5.5)$ \\
\hline
\end{tabular}

HbAlc glycated hemoglobin, SD standard deviation 
where necessary with data from other published sources (Table 1). The mean HbA1c at baseline was $8.6 \%(70 \mathrm{mmol} / \mathrm{mol})$, and use of RT-CGM led to a HbA1c reduction of $1.0 \%$ $(10 \mathrm{mmol} / \mathrm{mol})$ compared with a reduction of $0.4 \%(5 \mathrm{mmol} / \mathrm{mol})$ in the SMBG arm [1].

Hypoglycemic event rates were also sourced from the DIAMOND trial $[1,3]$. The rate of SHEs was 4.2 per 100 person-years in the RT-CGM arm and 12.2 per 100 person-years in the SMBG arm [1]. The rate of non-severe hypoglycemic events (NSHEs; defined as a series of $\geq 2$ glucose sensor values $<3.0 \mathrm{mmol} / \mathrm{l}[54 \mathrm{mg} / \mathrm{dl}]$ with a duration of at least $20 \mathrm{~min}$; obtained using blinded CGM in the SMBG arm) was 5840 per 100 person-years for RT-CGM and 10,950 per 100 person-years for the SMBG arm [3].

All clinical input data utilized in the analysis have been previously published elsewhere. Institutional review board approval was therefore not required.

\section{Costs and Health State Utilities}

The DIAMOND trial showed that the use of RTCGM reduced FoH, measured using the worry subscale of the Hypoglycemia Fear Survey (HFS). This QoL benefit was applied in the analysis by converting the 3.17-point reduction in FoH to a utility benefit of 0.02536 based on a previously published mapping of HFS scores to the EQ-5D [13]. A QoL benefit associated with the avoidance of fingerstick testing was also captured in the RT-CGM arm. Specifically, a utility benefit of 0.03 was applied, based on the findings of Matza et al. who quantified the QoL benefit associated with flash glucose monitoring relative to SMBG. As both flash glucose monitoring and the use of a factory calibrated RT-CGM system negate the need for fingerstick testing, it was assumed that this QoL benefit would also be applicable to RT-CGM [14]. Consequently, a total utility benefit of 0.05536 was applied to the RT-CGM arm.

For patients with no complications, a baseline utility value of 0.90 was assumed, based on the findings of the DIAMOND trial [4]. Disutilities associated with long-term diabetes-related complications and hypoglycemic events were derived from published sources $[15,16]$.

Intervention costs associated with the use of the Dexcom G6 RT-CGM system were based on current pricing for RT-CGM in France (including value added tax) and included 1 receiver, 36 sensors (based on a sensor lifetime of 10 days) and 4 transmitters. In the SMBG arm, the frequency of SMBG was assumed to be 4.6 tests per day, based on data from the DIAMOND study [1]; costs for strips, lancets and other SMBG supplies were based on current (2020) French social security list tariffs. Direct medical costs associated with diabetes-related complications were sourced from published literature, and where necessary costs were inflated to 2020 values using the consumer price index (health) (Table 2) [17-28].

\section{Sensitivity Analyses}

A series of one-way sensitivity analyses was performed to determine key drivers of outcomes. Sensitivity analyses were performed around treatment effects in terms of both HbA1c and hypoglycemic event rates. Specifically, analyses were performed in which the magnitude of the HbA1c reduction with RTCGM relative to SMBG was increased or decreased by $30 \%$. Analyses were also performed in which the hypoglycemic event rate for severe or non-severe hypoglycemic events was increased or decreased by $50 \%$ relative to the base case. The influence of the QoL benefit associated with reduced $\mathrm{FoH}$ and lack of fingerstick testing was also explored in analyses in which the magnitude of this benefit was increased or decreased by $50 \%$, and another analysis was performed in which the influence of baseline utility was explored using a baseline utility value of 0.672 sourced from the Sheffield type 1 diabetes policy model [29]. A series of sensitivity analyses were also performed around SMBG use in the SMBG arm in which frequencies of 4, 5.2 and 10 tests per day were explored (compared with 4.6 tests per day in the base case). The influence of the acquisition cost of the G6 RT-CGM system was also explored in a series of analyses in which the acquisition cost 
Table 2 Direct costs of diabetes-related complications

\begin{tabular}{|c|c|c|}
\hline Event & $\begin{array}{l}\text { Cost, } \\
\text { euros }\end{array}$ & Source \\
\hline Myocardial infarction, year of event & 15,723 & Lafuma et al. [17] \\
\hline Myocardial infarction, subsequent years & 1223 & Roze et al. [18] \\
\hline Angina, year of onset & 7228 & Lafuma et al. [17] \\
\hline Angina, subsequent years & 562 & Lafuma et al. [17] \\
\hline Congestive heart failure, year of onset & 3872 & Roze et al. [18] \\
\hline Congestive heart failure, subsequent years & 1895 & Roze et al. [18] \\
\hline Stroke, year of event & 16,750 & Chevreul et al. [19] \\
\hline Stroke, subsequent years & 8130 & Chevreul et al. [19] \\
\hline Stroke death within 30 days & 7077 & ATIH $[20]$ \\
\hline Peripheral vascular disease, annual & 329 & Ameli.fr [21], ecosante.fr [22] \\
\hline Hemodialysis, annual & 86,470 & Blotiére et al. [23] \\
\hline Peritoneal dialysis, annual & 62,895 & Blotiére et al. [23] \\
\hline Renal transplant, year of event & 84,385 & Blotiére et al. [23] \\
\hline Renal transplant, subsequent years & 19,844 & Blotiére et al. [23] \\
\hline Laser eye treatment & 192 & Launois et al. [24], Ameli.fr [21], ecosante.fr [22] \\
\hline Severe vision loss, year of event & 13,199 & Lafuma et al. [25] \\
\hline Cataract extraction, year of event & 1440 & ATIH $[20]$ \\
\hline Cataract extraction, subsequent years & 40 & Ameli.fr [21] \\
\hline Neuropathy, annual & 192 & Ameli.fr [21] \\
\hline Standard uninfected ulcer & 1223 & Ghatnekar et al. [26] \\
\hline Infected foot ulcer & 2146 & Ghatnekar et al. [26] \\
\hline Gangrene treatment & 3627 & Girod et al. [27] \\
\hline Amputation, year of event & 12,110 & Roze et al. [18] \\
\hline Amputation, prosthesis & 1682 & Ameli.fr [21] \\
\hline $\begin{array}{l}\text { Severe hypoglycemic event not requiring medical } \\
\text { assistance }\end{array}$ & 222 & Roze et al. [18] \\
\hline Severe hypoglycemic event requiring medical assistance & 4270 & Torreton et al. [28] \\
\hline
\end{tabular}

All costs are presented in 2020 EUR

ATIH Agence Technique de l'Information sur l'Hospitalisation

was increased or decreased by $5 \%, 15 \%$ or $25 \%$. Finally, the influence of a shorter time horizon was explored in sensitivity analyses run over time horizons of 10 and 25 years. 


\section{Perspective, Time Horizon and Discount Rate}

The analysis was performed from the payer perspective and the time horizon used was that of patient lifetimes. Future costs and clinical outcomes were discounted at a rate of $4 \%$ per annum in line with guidelines issued by Haute Autorité de Santé (HAS) [30].

\section{Compliance with Ethics Guidelines}

This article is based on previously conducted studies and does not contain any studies with human participants or animals performed by any of the authors.

\section{RESULTS}

In this long-term cost-effectiveness analysis based on clinical input data from the DIAMOND trial, the use of the Dexcom G6 RT-CGM system was projected to improve mean qualityadjusted life expectancy by 1.38 quality-adjusted life years (QALYs) compared with SMBG (10.64 QALYs for RT-CGM versus 9.26 QALYs for SMBG) (Table 3). Mean lifetime costs were 21,087 euros higher with RT-CGM $(148,077$ euros versus 126,990 euros), driven primarily by the higher costs associated with the RT-CGM device. The improved quality-adjusted life expectancy combined with higher costs resulted in an ICER of 15,285 euros per QALY gained for the G6 RT-CGM system versus SMBG. Although no official willingness-to-pay threshold exists in France, a benchmark of 50,000 euros is frequently used in cost-effectiveness analyses performed in Western Europe. Using this threshold, the likelihood of the G6 RT-CGM system being considered cost-effective relative to SMBG was $100 \%$.

Sensitivity analyses showed that assumptions around treatment effects in terms of HbA1c reduction and the QoL benefit associated with the combined effect of reduced $\mathrm{FoH}$ and lack of fingerstick testing were key drivers of results (Table 4). In an analysis in which the magnitude of the treatment effect was increased by $30 \%$ relative to the base case (i.e., a betweenarm difference in $\mathrm{HbA1c}$ of $0.9 \%$ at 24 weeks compared with $0.6 \%$ in the base case), the incremental gain in quality-adjusted life expectancy increased to 1.47 QALYs, resulting in the ICER decreasing to 10,749 euros per QALY gained. Conversely, if the HbA1c treatment effect was decreased by 30\%, the ICER increased to 21,140 euros per QALY gained. In the DIAMOND study, the treatment effect in terms of HbA1c reduction was shown to be strongly dependent on baseline HbA1c. In the overall T1D population, the HbA1c reduction in the RT-CGM arm was 1.0\%; however, in patients with baseline $\mathrm{HbA} 1 \mathrm{c} \geq 8.5 \%$ and $\geq 9.0 \%$, the corresponding reductions were $1.3 \%$ and $1.4 \%$, respectively (compared with $0.5 \%$ and $0.6 \%$, respectively, in the SMBG arm) [2]. Collectively, these results suggest that RTCGM is more cost-effective in those patients with the poorest glycemic control at baseline.

Table 3 Summary of base case results

\begin{tabular}{|c|c|c|c|}
\hline & $\begin{array}{l}\text { Dexcom G6 RT- } \\
\text { CGM }\end{array}$ & SMBG & Difference \\
\hline Total mean direct costs, euros & 148,077 & 126,990 & 21,087 \\
\hline Mean quality-adjusted life expectancy, QALYs & 10.635 & 9.255 & 1.38 \\
\hline ICER, euros per QALY gained & 15,285 & & \\
\hline $\begin{array}{l}\text { Probability of cost-effectiveness at a WTP threshold of 50,000 euros per } \\
\text { QALY gained }\end{array}$ & 100 & & \\
\hline
\end{tabular}

ICER incremental cost-effectiveness ratio, $Q A L Y$ quality-adjusted life year, $R T$-CGM real-time continuous glucose monitoring, $S M B G$ self-monitoring of blood glucose, WTP willingness-to-pay 
Table 4 Summary findings of sensitivity analyses

\begin{tabular}{|c|c|c|c|c|c|c|c|}
\hline \multirow[t]{2}{*}{ Analysis } & \multicolumn{2}{|c|}{ Cost, euros } & \multicolumn{4}{|c|}{$\begin{array}{l}\text { Quality-adjusted life expectancy, } \\
\text { QALYs }\end{array}$} & \multirow{2}{*}{$\begin{array}{l}\text { ICER, euros } \\
\text { per QALY } \\
\text { gained }\end{array}$} \\
\hline & $\begin{array}{l}\text { Dexcom } \\
\text { G6 RT- } \\
\text { CGM }\end{array}$ & SMBG & Difference & $\begin{array}{l}\text { Dexcom } \\
\text { G6 RT- } \\
\text { CGM }\end{array}$ & SMBG & $\overline{\text { Difference }}$ & \\
\hline Base case & 148,077 & 126,990 & 21,087 & 10.635 & 9.255 & 1.380 & 15,285 \\
\hline $\begin{array}{l}\text { RT-CGM HbAlc treatment } \\
\text { effect }-30 \%\left(0.3 \%{ }^{\mathrm{a}}\right)\end{array}$ & 153,970 & 126,990 & 26,979 & 10.531 & 9.255 & 1.276 & 21,140 \\
\hline $\begin{array}{l}\text { RT-CGM HbAlc treatment } \\
\text { effect }+30 \%\left(0.9 \%{ }^{\mathrm{a}}\right)\end{array}$ & 142,750 & 126,990 & 15,760 & 10.721 & 9.255 & 1.466 & 10,749 \\
\hline RT-CGM SHE rate - 50\% & 146,569 & 126,990 & 19,579 & 10.643 & 9.255 & 1.388 & 14,104 \\
\hline RT-CGM SHE rate + 50\% & 149,531 & 126,990 & 22,541 & 10.616 & 9.255 & 1.360 & 16,569 \\
\hline $\begin{array}{l}\text { RT-CGM NSHE } \\
\text { rate }-50 \%\end{array}$ & 148,077 & 126,990 & 21,087 & 10.830 & 9.255 & 1.575 & 13,387 \\
\hline $\begin{array}{l}\text { RT-CGM NSHE } \\
\text { rate }+50 \%\end{array}$ & 148,077 & 126,990 & 21,087 & 10.575 & 9.255 & 1.320 & 15,972 \\
\hline $\begin{array}{l}\text { RT-CGM utility } \\
\text { benefit }-50 \% \\
(+0.02768)\end{array}$ & 148,076 & 126,989 & 21,087 & 10.176 & 9.255 & 0.921 & 22,888 \\
\hline $\begin{array}{l}\text { RT-CGM utility } \\
\text { benefit }+50 \% \\
(+0.08304)\end{array}$ & 148,076 & 126,989 & 21,087 & 11.093 & 9.255 & 1.838 & 11,474 \\
\hline Number of SMBG/day $=4$ & 148,077 & 125,669 & 22,408 & 10.635 & 9.255 & 1.380 & 16,243 \\
\hline $\begin{array}{l}\text { Number of } \\
\text { SMBG/day }=5.2\end{array}$ & 148,077 & 128,845 & 19,232 & 10.635 & 9.255 & 1.380 & 13,941 \\
\hline Number of SMBG/day $=10$ & 148,077 & 141,526 & 6,551 & 10.635 & 9.255 & 1.380 & 4,748 \\
\hline $\begin{array}{l}\text { Utility T1D no } \\
\text { complications }=0.672\end{array}$ & 148,077 & 126,990 & 21,087 & 9.730 & 8.409 & 1.320 & 15,972 \\
\hline RT-CGM cost $+5 \%$ & 150,650 & 126,990 & 23,660 & 10.635 & 9.255 & 1.380 & 17,145 \\
\hline RT-CGM cost + 15\% & 155,785 & 126,990 & 28,795 & 10.635 & 9.255 & 1.380 & 20,866 \\
\hline RT-CGM cost + 25\% & 160,920 & 126,990 & 33,930 & 10.635 & 9.255 & 1.380 & 24,587 \\
\hline RT-CGM cost $-5 \%$ & 145,515 & 126,990 & 18,525 & 10.635 & 9.255 & 1.380 & 13,424 \\
\hline RT-CGM cost $-15 \%$ & 140,537 & 126,990 & 13,547 & 10.635 & 9.255 & 1.380 & 9,817 \\
\hline RT-CGM cost - 25\% & 135,247 & 126,990 & 8,257 & 10.635 & 9.255 & 1.380 & 5,983 \\
\hline Time horizon 10 years & 47,760 & 32,939 & 14,822 & 5.096 & 4.496 & 0.599 & 24,736 \\
\hline
\end{tabular}


Table 4 continued

\begin{tabular}{|c|c|c|c|c|c|c|c|}
\hline \multirow[t]{2}{*}{ Analysis } & \multicolumn{2}{|c|}{ Cost, euros } & \multicolumn{4}{|c|}{$\begin{array}{l}\text { Quality-adjusted life expectancy, } \\
\text { QALYs }\end{array}$} & \multirow{2}{*}{$\begin{array}{l}\text { ICER, euros } \\
\text { per QALY } \\
\text { gained }\end{array}$} \\
\hline & $\begin{array}{l}\text { Dexcom } \\
\text { G6 RT- } \\
\text { CGM }\end{array}$ & SMBG & Difference & $\begin{array}{l}\text { Dexcom } \\
\text { G6 RT- } \\
\text { CGM }\end{array}$ & SMBG & Difference & \\
\hline Time horizon 25 years & 104,928 & 83,776 & 21,152 & 9.027 & 7.925 & 1.102 & 19,189 \\
\hline
\end{tabular}

FoH fear of hypoglycemia, ICER incremental cost-effectiveness ratio, NSHE non-severe hypoglycemic event, $Q A L Y$ qualityadjusted life year, $R T$-CGM real-time continuous glucose monitoring, $S H E$ severe hypoglycemic event, $S M B G$ self-monitoring of blood glucose, T1D type 1 diabetes

Assumptions around the cost of RT-CGM and the QoL benefit in the RT-CGM arm were also key determinants of cost effectiveness. If the utility benefit was reduced by $50 \%$ to 0.02768 , the ICER increased substantially to 22,888 euros per QALY gained. Similarly, if this utility benefit was increased by $50 \%$, the incremental gain in quality-adjusted life expectancy increased to 1.84 QALYs, resulting in the ICER decreasing to 11,474 euros per QALY gained. A series of analyses was performed in which the cost of RT-CGM was increased or decreased by $5 \%, 15 \%$ or $25 \%$. Increasing the acquisition cost of RT-CGM by $25 \%$ increased the ICER substantially relative to the base case to 24,587 euros per QALY gained; however, a $25 \%$ reduction in the acquisition cost for RT-CGM resulted in an ICER of 5983 euros per QALY gained.

\section{DISCUSSION}

The findings of long-term health economic analyses suggest that, for adults based in France with long-standing T1D and poor glycemic control, the use of the G6 RT-CGM system is likely to be cost-effective relative to usual care with SMBG when considered from the payer perspective. The use of RT-CGM was projected to result in an incremental gain in quality-adjusted life expectancy of 1.38 QALYs relative to the use of SMBG alone. This benefit was attributable to the combined effects of improved glycemic control and the QoL benefit with RT-CGM conferred by reduced FoH and the elimination of the need for fingerstick testing.

Sensitivity analysis revealed that the results of the analysis were highly sensitive to the magnitude of the QoL benefit associated with $\mathrm{FoH}$ and no fingerstick testing. $\mathrm{FoH}$ has been shown to be common in people with T1D, particularly in those with a history of SHEs [31]. The extent to which FoH influences everyday life and disease management can vary considerably between patients, but in a substantial proportion of patients $\mathrm{FoH}$ is a key contributor to poor glycemic control. In France specifically, a 2013 observational study in people with longstanding T1D reported that over $70 \%$ of patients failed to achieve individualized glycemic control targets. Treating physicians believed that for approximately $40 \%$ of those not achieving target HbA1c levels, this failure was either partly or wholly attributable to FoH. Moreover, this effect increased with age; in people aged $\geq$ 50 years, FoH was believed to be the sole or main contributing factor to poor control in 54\% of patients not achieving glycemic targets [32]. The same study also showed that $23 \%$ of patients deliberately decreased their insulin dose because of FoH, 27\% avoided driving and $39 \%$ avoided exercise. FoH was also shown to have a negative impact on some patients' professional lives, with almost a quarter of patients reporting that they had declined work-related tasks or responsibilities owing to $\mathrm{FoH}$ [32].

The Urgent Low Soon Alert that allows patients to take pre-emptive action to prevent hypoglycemic events is likely to be a key factor 
in reducing $\mathrm{FoH}$, particularly as many patients may not immediately recognize the onset of hypoglycemia. Findings from a multinational study showed that for adults with T1D based in France, the mean time taken to recognize an NSHE was $1.5 \mathrm{~h}$, the mean time spent responding was $1.4 \mathrm{~h}$, and the mean time spent recovering was $17.1 \mathrm{~h}$ [33]. The length of time taken to recover from an NSHE suggests that even non-severe events may have an effect on indirect costs in terms of lost productivity; however, the current analysis was performed from the payer perspective, and lost-productivity was not accounted for. If considered from a societal perspective, the potential effect of a reduction in the incidence of NSHEs may further increase the cost-effectiveness of RT-CGM relative to SMBG.

The ramifications of $\mathrm{FoH}$ also extend beyond the patient to family members and caregivers, particularly to parents of young patients. The most recent RT-CGM systems including the G6 RT-CGM system (and the previous generation G5 system) allow for real-time remote monitoring of blood glucose levels using smart devices. The benefits of remote monitoring are specifically mentioned in the 2018 French position statement on CGM, noting that this facility is of particular value for children as well as non-autonomous and isolated adults. All disease remote monitoring has proved invaluable recently during the 2020 COVID-19 pandemic. Prior to the pandemic, in France, the volume of telemedicine consultations was < 10,000 per week. However, by the last week of March 2020, this had increased to $>450,000$ per week [34]. For T1D specifically, the ease with which RT-CGM data can be shared with healthcare providers has been highlighted as a key facilitator of effective telemedicine [35, 36]. Earlier studies have also shown that remote monitoring has alleviated anxiety, particularly around nocturnal hypoglycemic events, in parents of young children with T1D [7].

As well as the effect on FoH, users of RT-CGM have reported high levels of satisfaction with RT-CGM in terms of improving their understanding of disease and individual glucose level profiles. In qualitative interviews RT-CGM users have reported that being able to see both the direction and rate of change in glucose levels has provided them with the ability to make more informed decisions with regard to timing of meals and snacks, exercise and insulin doses [37]. In the same study, RT-CGM users also appreciated the discretion afforded by modern devices, with one user describing the simplicity of checking glucose levels as being analogous to telling the time. Performing SMBG testing in front of other people can be a barrier for some patients. A recent study showed that in France only $29 \%$ of people with T1D fulfill the HAS recommendations of performing SMBG at least four times per day, with the surrounding environment often presenting a barrier. Overall, in people with diabetes (including those with type 2 diabetes), only $42-56 \%$ felt comfortable performing SMBG in front of friends and only $17-24 \%$ stated that they would be comfortable performing SMBG in front of colleagues [38].

The scope of the current analysis was limited to the long-term cost-effectiveness of RT-CGM versus SMBG; the budget impact of the introduction of the Dexcom G6 RT-CGM system was not investigated. The budget impact of new technologies such as new RT-CGM devices is governed by the extent of demand and uptake in routine clinical practice. Figures from the HAS estimate that between 22,400 and 40,000 patients would be eligible for the Dexcom G6 RT-CGM system per year. However, French guidelines recommend that patients use the device for a 1-month trial period before initiating long-term RT-CGM use. RT-CGM requires adherence and commitment from the patient, and not all patients may be willing to wear the sensor for the recommended amount of time, which may compromise both the clinical and long-term cost-effectiveness of the use of the device. Real-world data from other European countries reveal that for the G6 RT-CGM system the median weekly utilization is 6.8 days per week (Dexcom, data on file). Similarly, in the DIAMOND trial at 24 weeks, median utilization of RT-CGM was 7.0 days per week, and $93 \%$ of patients used RT-CGM for 6 days a week or more [1].

The current analysis is associated with a number of limitations. In particular, a key 
limitation inherent in long-term cost-effectiveness analyses is the use of short-term clinical trial data to project long-term outcomes. However, the duration of clinical trials is typically not sufficient to capture long-term outcomes; therefore, in the absence of such data modeling represents one of the best available alternative approaches. It should also be noted that another limitation of the analysis is that in the absence of head-to-head trials of the G6 RTCGM system, it was necessary to use clinical input data from the DIAMOND trial, which used the earlier G4 RT-CGM system. However, although factory calibration and the longer sensor lifetime of the G6 system were factored in, other advances with the G6 relative to the G4 system (e.g., Urgent Low Soon Alert) mean that the current analysis may potentially represent a conservative scenario.

\section{CONCLUSIONS}

Overall, the findings of the current analysis suggest that for adults with T1D with poor glycemic control and/or problematic hypoglycemia the use of the G6 RT CGM is a costeffective management option relative to SMBG alone based on a willingness-to-pay threshold of 50,000 euros per QALY gained.

\section{ACKNOWLEDGEMENTS}

Funding. This analysis was funded by Dexcom. Funding by Dexcom also included the journal's rapid service fee.

Authorship. All named authors meet the International Committee of Medical Journal Editors (ICMJE) criteria for authorship for this article, take responsibility for the integrity of the work as a whole, and have given their approval for this version to be published.

Disclosures. Stéphane Roze and John J. Isitt are current employees of Vyoo Agency, which has received consulting fees from Dexcom. Jayne Smith-Palmer is a current employee of
Ossian Health Economics and Communications, which has received consulting fees from Dexcom. Peter Lynch, Brigitte Klinkenbijl and Gerald Zammit are current employees of Dexcom, which manufactures the G6 RT-CGM system. Pierre-Yves Benhamou has received speaker honoraria from Abbott, Roche, Eli Lilly, Novo Nordisk and Sanofi and served on advisory board panels for Abbott, Diabeloop, Roche, Medtronic, Dexcom, Insulet, Lifescan, Eli Lilly, Novo Nordisk and Sanofi.

Compliance with Ethics Guidelines. All clinical input date used in this analysis have been previously published. The analysis does not contain any studies with human participants or animals performed by any of the authors.

Data Availability. The datasets generated during and/or analyzed during the current study are available from the corresponding author on reasonable request.

Open Access. This article is licensed under a Creative Commons Attribution-NonCommercial 4.0 International License, which permits any non-commercial use, sharing, adaptation, distribution and reproduction in any medium or format, as long as you give appropriate credit to the original author(s) and the source, provide a link to the Creative Commons licence, and indicate if changes were made. The images or other third party material in this article are included in the article's Creative Commons licence, unless indicated otherwise in a credit line to the material. If material is not included in the article's Creative Commons licence and your intended use is not permitted by statutory regulation or exceeds the permitted use, you will need to obtain permission directly from the copyright holder. To view a copy of this licence, visit http://creativecommons.org/licenses/by$\mathrm{nc} / 4.0 /$. 


\section{REFERENCES}

1. Beck RW, Riddlesworth T, Ruedy $\mathrm{K}$, Ahmann A, Bergenstal R, Haller S, Kollman C, Kruger D, McGill JB, Polonsky W, Toschi E, Wolpert H, Price D, DIAMOND Study Group. Effect of continuous glucose monitoring on glycemic control in adults with type 1 diabetes using insulin injections: the DIAMOND randomized clinical trial. JAMA. 2017;317(4):371-8.

2. Billings LK, Parkin CG, Price D. Baseline glycated hemoglobin values predict the magnitude of glycemic improvement in patients with type 1 and type 2 diabetes: subgroup analyses from the DIAMOND study program. Diabetes Technol Ther. 2018;20(8):561-5.

3. Riddlesworth T, Price D, Cohen N, Beck RW. Hypoglycemic event frequency and the effect of continuous glucose monitoring in adults with type 1 diabetes using multiple daily insulin injections. Diabetes Ther. 2017;8(4):947-51.

4. DIAMOND Study Group. The impact of continuous glucose monitoring on markers of quality of life in adults with type 1 diabetes: further findings from the DIAMOND randomized clinical trial. Diabetes Care. 2017;40(6):736-41.

5. Sørgård $\mathrm{B}$, Iversen MM, Mårtensson J. Continuous glucose monitoring in adults with type 1 diabetes: a balance between benefits and barriers: a critical incident study. J Clin Nurs. 2019;28(17-18): 3318-29.

6. Puhr S, Derdzinski M, Welsh JB, Parker AS, Walker T, Price DA. Real-world hypoglycemia avoidance with a continuous glucose monitoring system's predictive low glucose alert. Diabetes Technol Ther. 2019;21(4):155-8.

7. Burckhardt MA, Roberts A, Smith GJ, Abraham MB, Davis EA, Jones TW. The use of continuous glucose monitoring with remote monitoring improves psychosocial measures in parents of children with type 1 diabetes: a randomized crossover trial. Diabetes Care. 2018;41(12):2641-3.

8. Borot S, Benhamou PY, Atlan C, Bismuth E, Bonnemaison E, Catargi B, Société francophone du diabète (SFD), Société française d'endocrinologie (SFE); Évaluation dans le diabète des implants actifs Group (EVADIAC), et al. Practical implementation, education and interpretation guidelines for continuous glucose monitoring: a French position statement. Diabetes Metab. 2018;44(1):61-72.

9. Haute Autorité de Santé. 2020. DEXCOM G6, Système de mesure en continu du glucose interstitial. https://www.has-sante.fr/upload/docs/evamed/
CNEDIMTS-6061_DEXCOM\%20G6_25_f\%C3\%

A9vrier_2020_(6061)_avis.pdf. Accessed July 06, 2020.

10. Ministère des Solidarités et de la Santé. National Health Strategy 2018-2022. https://solidaritessante.gouv.fr/IMG/pdf/dossier_sns_2017 synthesev6-10p_anglaisv2.pdf. Accessed June 30, 2020.

11. Palmer AJ, Roze S, Valentine WJ, Minshall ME, Foos V, Lurati FM, Lammert M, Spinas GA. The CORE Diabetes Model: Projecting long-term clinical outcomes, costs and cost-effectiveness of interventions in diabetes mellitus (types 1 and 2) to support clinical and reimbursement decision-making. Curr Med Res Opin. 2004a;20(Suppl 1):S5-26.

12. Palmer AJ, Roze $S$, Valentine WJ, Minshall ME, Foos V, Lurati FM, Lammert M, Spinas GA. Validation of the CORE Diabetes Model against epidemiological and clinical studies. Curr Med Res Opin. 2004b;20(Suppl 1):S27-40.

13. Currie CJ, Morgan CL, Poole CD, Sharplin P, Lammert M, McEwan P. Multivariate models of healthrelated utility and the fear of hypoglycaemia in people with diabetes. Curr Med Res Opin. 2006;22(8):1523-34.

14. Matza LS, Stewart KD, Davies EW, Hellmund R, Polonsky WH, Kerr D. Health state utilities associated with glucose monitoring devices. Value Health. 2017;20(3):507-51.

15. Beaudet A, Clegg J, Thuresson PO, Lloyd A, McEwan P. Review of utility values for economic modeling in type 2 diabetes. Value Health. 2014;17(4): 462-70.

16. Evans M, Khunti K, Mamdani M, Galbo-Jørgensen $\mathrm{CB}$, Gundgaard J, Bøgelund M, Harris S. Health-related quality of life associated with daytime and nocturnal hypoglycaemic events: a time trade-off survey in five countries. Health Qual Life Outcomes. 2013;3(11):90.

17. Lafuma A, Colin X, Solesse A. Cost-effectiveness of atorvastatin in the prevention of cardiovascular events in diabetic patients: a French adaptation of CARDS. Arch Cardiovasc Dis. 2008;101(5):327-32.

18. Roze S, Smith-Palmer J, Valentine W, Payet V, de Portu S, Papo N, Cucherat M, Hanaire H. Cost-effectiveness of sensor-augmented pump therapy with low glucose suspend versus standard insulin pump therapy in two different patient populations with type 1 diabetes in France. Diabetes Technol Ther. 2016;18(2):75-84. 
19. Chevreul K, Durand-Zaleski I, Gouépo A, Fery-Lemonnier E, Hommel M, Woimant F. Cost of stroke in France. Eur J Neurol. 2013;20(7):1094-100.

20. Agence technique de l'information sur l'hospitalisation. National hospital costs by DRG. https:// www.scansante.fr/. Accessed July 02, 2020.

21. Ameli.fr. https://www.ameli.fr/. Accessed July 02. 2020.

22. Ecosante.fr. https://ecosante.fr/index2.php?base $=$ DEPA\&langh=FRA\&langs=FRA. Accessed July 02, 2020.

23. Blotière PO, Tuppin $\mathrm{P}$, Weill $\mathrm{A}$, Ricordeau $\mathrm{P}$, Allemand $\mathrm{H}$. Coût de la prise en charge de l'IRCT en France en 2007 et impact potentiel d'une augmentation du recours à la dialyse péritonéale et à la greffe [The cost of dialysis and kidney transplantation in France in 2007, impact of an increase of peritoneal dialysis and transplantation]. Nephrol Ther. 2010;6(4):240-7.

24. Launois R, Le Moine J-G, Raimond V, Maunoury F, Daher I, Dessaigne A. Evaluation Economique du Dépistage de la Rétinopathie Diabétique par Photographies du Fond d'Oeil. https://congres.eska.fr/ pdf/EM\%202012\%20rlaunois_

presentationretinopathie.pdf. Accessed July 02, 2020.

25. Lafuma A, Brezin A, Fagnani F, Mimaud V, Mesbah M, Berdeaux G. Nonmedical economic consequences attributable to visual impairment: a nation-wide approach in France. Eur J Health Econ. 2006;7(3):158-64.

26. Ghatnekar O, Willis M, Persson U. Cost-effectiveness of treating deep diabetic foot ulcers with Promogran in four European countries. J Wound Care. 2002;11(2):70-4.

27. Girod I, Valensi P, Laforêt C, Moreau-Defarges T, Guillon P, Baron F. An economic evaluation of the cost of diabetic foot ulcers: results of a retrospective study on 239 patients. Diabetes Metab. 2003;29(3): 269-77.

28. Torreton T, Vandebrouck T, Emiel P, Detournay B. Cost of inpatient management of hypoglycemia in France. Value Health. 2013;16(7):436.

29. The Sheffield Type 1 Diabetes Policy Model. https:// www.sheffield.ac.uk/scharr/sections/heds/ discussion-papers/1305-1.258469. Accessed July 01, 2020.

30. Haute Autorité de Santé. Choix méthodologiques pour l'évaluation économique à la HAS. 2011. https://www.has-sante.fr/upload/docs/application/ pdf/2011-11/guide_methodo_vf.pdf. Accessed July 01, 2020.

31. Anderbro T, Gonder-Frederick L, Bolinder J, Lins PE, Wredling R, Moberg E, Lisspers J, Johansson UB. Fear of hypoglycemia: relationship to hypoglycemic risk and psychological factors. Acta Diabetol. 2015;52(3):581-9.

32. Böhme P, Bertin E, Cosson E, Chevalier N, GEODE Group. Fear of hypoglycaemia in patients with type 1 diabetes: do patients and diabetologists feel the same way? Diabetes Metab. 2013;39(1):63-70.

33. Brod M, Christensen T, Bushnell DM. The impact of non-severe hypoglycemic events on daytime function and diabetes management among adults with type 1 and type 2 diabetes. J Med Econ. 2012;15(5): 869-77.

34. Le Figaro. 2010. Coronavirus, confinement: près de 500.000 téléconsultations en une semaine. https:// www.lefigaro.fr/flash-actu/coronavirus-explosiondes-teleconsultations-en-mars-en-france-20200331. Accessed July 20, 2020.

35. Garg SK, Rodbard D, Hirsch IB, Forlenza GP. Managing new-onset type 1 diabetes during the COVID-19 pandemic: challenges and opportunities. Diabetes Technol Ther. 2020;22(6):431-9.

36. Advanced Technologies and Treatments for Diabetes 2020. COVID-19 and diabetes. https://www. attd-education.com/course/index.php?categoryid= 20. Accessed July 20, 2020.

37. Lawton J, Blackburn M, Allen J, Campbell F, Elleri D, Leelarathna L, Rankin D, Tauschmann M, Thabit H, Hovorka R. Patients' and caregivers' experiences of using continuous glucose monitoring to support diabetes self-management: qualitative study. BMC Endocr Disord. 2018;18(1):12.

38. Guerci B, Benhamou PY, Durain D, Bahloul A, Jeanbat V, Detournay B. Pratique de l'auto-surveillance glycémique en France: données d'une enquête nationale [Self-monitoring of blood glucose in France: data from a national survey]. Sante Publique. 2017;29(2):229-40. 